\title{
The inter- and intra-rater reliability of the Maestro and Barroco metatarsal length measurement techniques
}

\author{
Zainab Ali", Hassan Karim, Navid Wali and Reza Naraghi
}

\begin{abstract}
Background: The relationship between metatarsal length and various forefoot pathologies is a topic of contention in Orthopaedics. The results of such investigations have been shown to depend on the method of metatarsal length measurement used. The aim of this study was to assess the inter- and intra-rater reliability of the Maestro and Barroco metatarsal length measurement techniques.

Methods: A retrospective and quantitative study was performed on 15 randomly selected radiographs to determine the reliability of the two measurement techniques across all five metatarsals (M1 to M5). This was done at one week apart for three weeks by three raters. The intraclass correlation coefficient (ICC), and the 95\% lower confidence limit (95\% LCL) were calculated.

Results: The Maestro and Barroco techniques produced high to very high ICC vlaues for length measurements across all metatarsals. The 95\% lower confidence limit for inter-rater measurements ranged between 0.92-0.98 for Maestro's and 0.86-0.99 for Barroco's technique. For intra-rater measurements the 95\% LCL ranged between 0.83-0. 99 for Maestro's and 0.75-0.99 for Barroco's technique.

Conclusions: Our study found that both the Maestro and Barroco methods of measurements produced high to very high inter- and intra-rater reliability. Both methods may be suitable for the use of peri-operative planning and clinical research relating metatarsal length and forefoot pathology. Besides having a more simplistic method of application, the novel Barroco technique is comparable to the more established Maestro method in both repeatability and reproducibility.
\end{abstract}

Keywords: Metatarsal length, Reliability, Radiographic measurements, Maestro technique, Barroco technique

\section{Background}

Metatarsal length has been an area of contention in Podiatric Medicine. Different forefoot morphologies due to variation in first metatarsal length relative to the 2nd metatarsal has led to multiple terms, such as Greek foot (index minus), Egyptian foot (index plus) and Roman foot (index plus-minus) as depicted in Fig. 1 [1]. These forefoot morphologies have been controversial in the literature, especially in relation to normality and possible association with forefoot pathology [1-9]. Metatarsal

\footnotetext{
* Correspondence: Zainsg14@gmail.com

University of Western Australia, School of Surgery, Podiatric Medicine, Crawley, Western Australia 6009, Australia
}

length and its association to hallux abductovalgus [10-15], Morton's neuroma [16], forefoot plantar pressures [17-21] and metatarsophalangeal joint instability [22] have all been investigated.

However it is generally accepted that too long or too short metatarsal length can lead to forefoot pathologies [3, 23, 24]. Many forefoot corrective surgeries involve metatarsal shortening indicating a potential link between metatarsal length and forefoot pathologies [25-27]. A study by Pérez-Muñoz et al. tested the efficacy of Weil and triple Weil osteotomies for the treatment of metatarsalgia $(n=93 \mathrm{ft}$ ) [26]. Prior to surgery, majority of feet were classified as index-minus $(n=75)$. Post-operatively, the foot morphology was altered such that the majority were categorised as index plus-minus $(n=81)$. The

(c) The Author(s). 2018 Open Access This article is distributed under the terms of the Creative Commons Attribution 4.0 International License (http://creativecommons.org/licenses/by/4.0/), which permits unrestricted use, distribution, and 


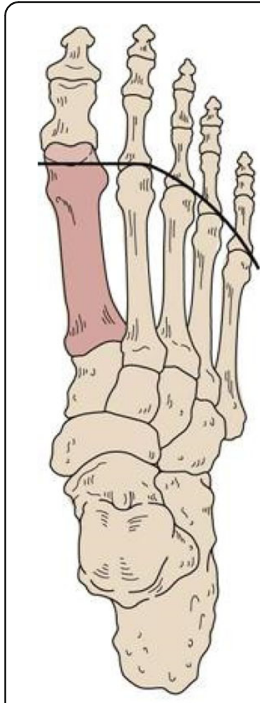

Index plus

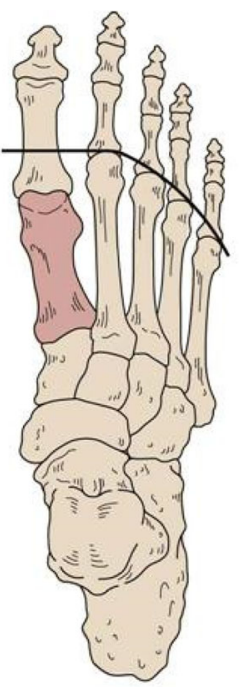

Index minus

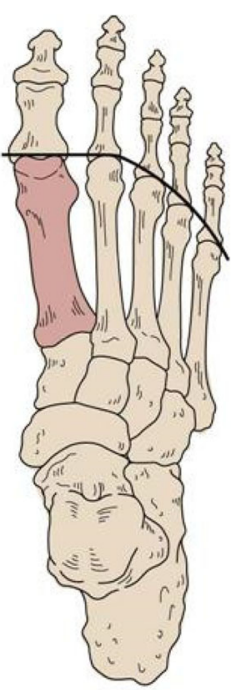

Index plus-minus
Fig. 1 Forefoot morphotypes: Index-plus foot is also known as Egyptian foot. Index-minus foot is also known as Morton's foot type or Greek foot. Index plus-minus foot is also known as the Roman foot

authors noted good surgical results in $80 \%$ of the patients. Similar positive surgical outcomes were obtained by Devos Bevernage and Leemrijse study that used Maestro's measurement tool for preoperative planning of Weil osteotomy [28]. Other studies have attained comparable findings in support of metatarsal shortening to relieve forefoot pain, even in regards to Morton's neuroma $[24,27,29]$. However, there have been reports of surgical alterations in literature that have resulted in increased weight transfer to adjacent metatarsals post-operatively [30, 31]. This highlights the importance of a reliable radiographic measurement tool for peri-operative planning.

The method used in determining the extent of metatarsal shortening varies between surgeons and is widely undescribed [24, 32-34]. Davies and Saxby [34] proposed to shorten the lesser metatarsal until the tension on the surrounding soft tissue was released and the metatarsal-phalangeal joint was reduced. They would only shorten the second metatarsal up to $5 \mathrm{~mm}$ and would take extra care not to reduce it more than the third metatarsal in order to avoid transfer lesions. Some surgeons explicitly rely on Maestro's idea of maintaining a "harmonious curve" to assure physiological function and correct weight distribution at the forefoot [32]. The harmonious forefoot morphotype is described as a geometrical progression of the relative lengths of the lesser metatarsals (eg. $1 \leq 2>3>4>5$ ) by a factor of two and deviations from this norm are considered to result in "disharmony" and hence result in a symptomatic forefoot [35]. As metatarsal shortening of as little as $2 \mathrm{~mm}$ can cause recurrence and transfer metatarsalgia [32], this further necessitates the use of a precise measurement technique in preoperative planning.

To date, there is no gold standard radiographic method for measuring metatarsal lengths [21] and there is a lack of agreement between different measurements methods [22, 23, 36]. Morton's transverse lines' [5], Coughlin's [33], Maestro's [35] and Hardy and Clapham's $[3,10]$ methods are some of the commonly noted techniques in the literature [23]. Of these, Maestro's technique is readily applicable to all five metatarsals along with a new un-validated method by Barroco et al. [2]. Our objective was to investigate the reliability and practicality of these two techniques and validate their use in future studies and peri-operative settings.

\section{Methods}

The aim of this study was to assess the inter- and intra-rater reliability of the Maestro (Fig. 2a) and Barroco (Fig. 2b) techniques used to measure metatarsal length radiographically. A retrospective and quantitative study was performed at the University of Western Australia (UWA) podiatry clinic. Ethics approval was obtained prior to the study.

Fifteen weight-bearing dorsoplantar (DP) radiographs from participants aged between 20 to 65 years were

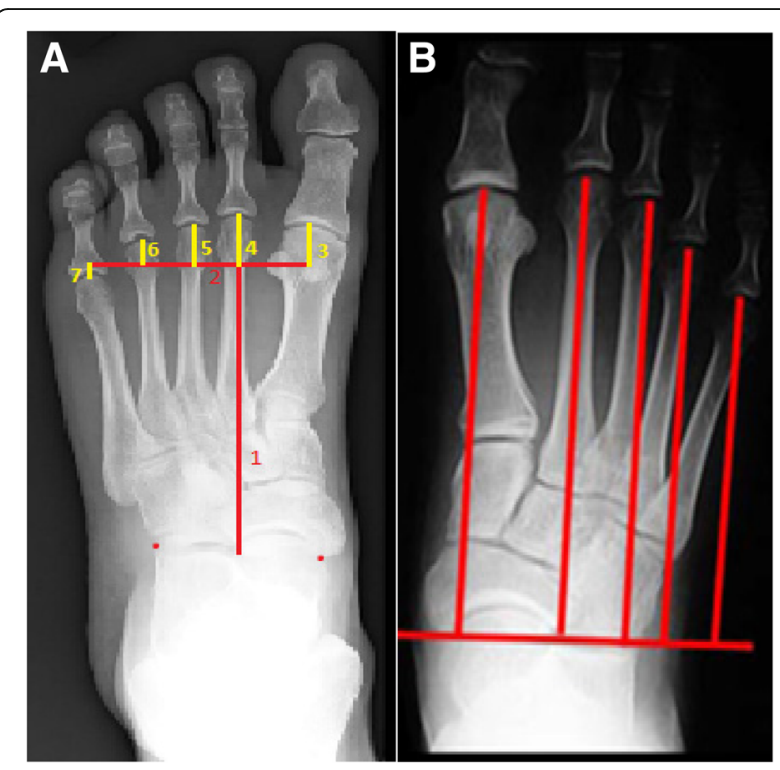

Fig. 2 a Maestro's technique involves seven lines; 1) Extends from the midpoint of the Chopart's joint to the distal apex of the second metatarsal head, 2) Perpendicular line bisects the fibular sesamoid and extends across the metatarsal heads [SM4 line], 3-7) Vertical lines extending from the distal tips of metatarsals $1-5$ to line 2 . $\mathbf{b}$ Barroco's technique involves six lines; Initially a proximal line is drawn extending between the most proximo-medial aspect of the navicular to the lateral congruence of the calcaneocuboid joint. A perpendicular line is then drawn from the apex of each metatarsal head to this proximal line 
selected at random. All participants had signed informed consent allowing their radiographs to be used for future research by students of the UWA podiatry clinic. Participants were screened through the Genie Medical Software to exclude any remarkable forefoot deformities and surgical interventions, as highlighted by their medical history.

Three final year post-graduate podiatry students were initially trained by a specialist podiatric surgeon to conduct the radiographic measurements using the Digital Imaging and Communications in Medicine (DICOM) program, InteleViewer. Each of the three raters measured all five metatarsal lengths using both techniques within the same setting and time. Each rater conducted measurements in an isolated cubicle within the clinic. This was carried out at one-week intervals for three weeks. The digital weightbearing DP radiographs of the 15 participants were obtained through Perth radiology clinic, SKG and Imaging Central databases.

In order to determine the intra- and inter-rater reliability of the measurement techniques, intraclass correlation coefficients (ICCs) and the 95\% lower confidence limit (95\% LCL) were calculated for the lengths of metatarsal one (M1) to metatarsal five (M5). A two way mixed effect model with absolute agreement was utilized for calculating ICCs. The single measures ICCs were used as the measure of intra-rater reliability. The average measures ICCs were used as the measure of inter-rater reliability. The test was chosen to show if the measurements were in agreement within and between the raters. The reliability was regarded as minimal for $\mathrm{ICC} \leq 0.25$, low for ICC between 0.26 to 0.49 , moderate for ICC between 0.50 to 0.69 , high for ICC between 0.70 to 0.89 or very high for ICC $\geq 0.90$ as originally used by Shima et al. [37]. According to a review article on determination of sample size requirements for estimating the value of intraclass correlation coefficient, for an ICC value above 0.80 , total number of subjects needed were 6 , with 3 measurements per subject to give the study $90 \%$ power [38]. Our study included 15 subjects with 3 measurement-repeats on each subject and depicted ICC values $>0.80$. This allowed the study $90 \%$ power to reach valid conclusions on intra and inter-rater measurement reliabilities.

\section{Results}

The mean and standard error of the mean (SEM) values in centimetre for each metatarsal length by each rater is given for Maestro and Barroco's technique in Tables 1 and 2 respectively.

\section{The inter-rater reliability}

The inter-rater reliability results for the metatarsal length measurement for each week for Maestro's and
Table 1 Mean metatarsal length with SEM (in cm) for Maestro's technique

\begin{tabular}{lll}
\hline Maestro measurements & Mean N=45 & SEM \\
\hline Met_1_R1 & 1.218 & .027 \\
Met_1_R2 & 1.249 & .025 \\
Met_1_R3 & 1.206 & .028 \\
Met_2_R1 & 1.531 & .039 \\
Met_2_R2 & 1.554 & .039 \\
Met_2_R3 & 1.517 & .039 \\
Met_3_R1 & 1.095 & .045 \\
Met_3_R2 & 1.121 & .047 \\
Met_3_R3 & 1.076 & .046 \\
Met_4_R1 & .251 & .044 \\
Met_4_R2 & .286 & .046 \\
Met_4_R3 & .239 & .044 \\
Met_5_R1 & -1.145 & .039 \\
Met_5_R2 & -1.129 & .040 \\
Met_5_R3 & -1.170 & .041 \\
\hline
\end{tabular}

Measurement data for each metatarsal by each rater was pooled from 15 subjects and 3 repeats per subject over three weeks, and mean and SEM calculated. $M$ Metatarsal, $R$ Rater

Barroco's techniques are shown in Tables 3, 4 and 5. For Maestro's technique, the 95\% LCL of the ICC for measuring metatarsal length between raters exceeded 0.90 across all metatarsals, and the LCL values ranged 0.92 to 0.98. For Barroco's technique, the 95\% LCL was marginally below the 0.90 level for metatarsal five (M5)

Table 2 Mean metatarsal length with SEM (in cm) for Barroco's technique

\begin{tabular}{llr}
\hline Barroco measurements & Mean N $=45$ & SEM \\
\hline Met_1_R1 & 12.251 & .161 \\
Met_1_R2 & 12.316 & .156 \\
Met_1_R3 & 12.304 & .145 \\
Met_2_R1 & 12.491 & .181 \\
Met_2_R2 & 12.364 & .172 \\
Met_2_R3 & 12.488 & .169 \\
Met_3_R1 & 11.997 & .180 \\
Met_3_R2 & 11.820 & .166 \\
Met_3_R3 & 11.979 & .168 \\
Met_4_R1 & 11.104 & .171 \\
Met_4_R2 & 10.855 & .156 \\
Met_4_R3 & 11.072 & .160 \\
Met_5_R1 & 9.668 & .154 \\
Met_5_R2 & 9.341 & .143 \\
Met_5_R3 & 9.608 & .146 \\
\hline Measurement & &
\end{tabular}

Measurement data for each metatarsal by each rater was pooled from 15 subjects and 3 repeats per subject over three weeks, and mean and SEM calculated. $M$ Metatarsal, $R$ Rater 
Table 3 Intraclass correlation coefficients and 95\% lower confidence limit on measurements of raters from week one

\begin{tabular}{llllll}
\hline Metatarsals & \multicolumn{2}{l}{ Barroco } & & \multicolumn{2}{l}{ Maestro } \\
\cline { 2 - 3 } & ICC & LCL & & ICC & LCL \\
\hline M1 & 0.990 & 0.977 & & 0.983 & 0.960 \\
M2 & 0.988 & 0.970 & & 0.987 & 0.969 \\
M3 & 0.984 & 0.962 & & 0.994 & 0.986 \\
M4 & 0.971 & 0.927 & & 0.991 & 0.976 \\
M5 & 0.946 & 0.865 & & 0.991 & 0.978 \\
\hline
\end{tabular}

Two-way mixed effects model used where people effects are random and measures effects are fixed. Inter-rater ICCs are obtained using metatarsal 1-5 length measurements from all raters in week 1 , where $n=15$

measurements in the first two weeks but surpassed the 0.90 level by week three. The LCL values for metatarsal length measurement using Barroco's technique ranged between 0.86 to 0.99 . The $95 \%$ lower confidence limit values indicate that both Barroco's and Maestro's measurement techniques produce high to very high reliability in measuring length across all metatarsals.

\section{The intra-rater reliability}

The intra-rater reliability is presented in Tables 6 and 7 for Maestro's and Barroco's measurement techniques respectively using three repeats of the measurement by each rater. Considering the $95 \%$ lower confidence limit, the intraclass correlation coefficients for measurement of metatarsal lengths (M1 to M3) exceeded the 0.90 level for both measurement techniques. However for some raters, LCL was below the 0.90 level for metatarsal four (M4) measurement using Maestro's technique and M4 \& M5 measurement using Barroco's techniques. Where 95\% lower confidence limit ICC for M4 for both techniques were generally above 0.80 level; LCL for M5 ranged between 0.75-0.96 using Barroco's technique and 0.90-0.98 using Maestro's technique. Maestro technique showed a tendency to produce lower intra-rater variability in measuring M5 over Barroco's technique.

Table 4 Intraclass correlation coefficients and 95\% lower confidence limit on measurements of raters from week two

\begin{tabular}{llllll}
\hline Metatarsals & \multicolumn{2}{l}{ Barroco } & & & \multicolumn{2}{l}{ Maestro } \\
\cline { 2 - 3 } \cline { 5 - 6 } & ICC & LCL & & ICC & LCL \\
\hline M1 & 0.987 & 0.969 & & 0.982 & 0.944 \\
M2 & 0.992 & 0.981 & & 0.994 & 0.986 \\
M3 & 0.988 & 0.971 & 0.991 & 0.979 \\
M4 & 0.976 & 0.934 & 0.967 & 0.921 \\
\hline
\end{tabular}

Two-way mixed effects model used where people effects are random and measures effects are fixed. Inter-rater ICCs are obtained using metatarsal 1-5 length measurements from all raters in week 2 , where $N=15$
Table 5 Intraclass correlation coefficients and 95\% lower confidence limit on measurements of raters from week three

\begin{tabular}{llllll}
\hline Metatarsals & \multicolumn{2}{l}{ Barroco } & & \multicolumn{2}{l}{ Maestro } \\
\cline { 2 - 3 } & ICC & LCL & & ICC & LCL \\
\hline M1 & 0.993 & 0.983 & & 0.983 & 0.947 \\
M2 & 0.996 & 0.991 & & 0.992 & 0.977 \\
M3 & 0.995 & 0.986 & & 0.992 & 0.953 \\
M4 & 0.993 & 0.978 & & 0.974 & 0.938 \\
M5 & 0.988 & 0.959 & & 0.991 & 0.970 \\
\hline
\end{tabular}

Two-way mixed effects model used where people effects are random and measures effects are fixed, Inter-rater ICCs are obtained using metatarsal 1-5 length measurements from all raters in week 3 , where $N=15$

\section{Discussion}

The reproducibility (inter-rater reliability) of a test indicates the precision of a method and determines its validity and use in clinical practice [39]. The repeatability (intra-rater reliability) refers to the variation in repeat measurements by the same rater under identical conditions. The results from the present study showed that both the Maestro and Barroco methods depicted excellent levels of reproducibility and repeatability.

Maestro's method of measurement depicted inter-rater LCL values ranging from 0.921-0.986 across all five metatarsals, over the three weeks. Our study implies that the Maestro technique has very high reliability for all five metatarsals between raters. The intra-rater LCL values ranged from $0.832-0.998$ across all five metatarsals for the three raters. Overall, our results are in concordance with Maestro et al.'s original paper, which reported "excellent" reliability outcomes [35]. However, they failed to provide information on how they reached these conclusions [35]. Our results are further supported by Deleu et al. who found inter-rater ICC values ranging from $0.982-0.997$ and intra-rater ICC results between $0.981-0.997$ [32]. It is worth noting both our study and Deleu et al. used Maestro's technique for metatarsal length measurement. However, their ICC values were based on the agreement of two observers in regards to forefoot morphotype classification, and hence they fail

Table 6 Intraclass correlation coefficients and 95\% lower confidence limit within rater measurements for Maestro's measurement technique

\begin{tabular}{|c|c|c|c|c|c|c|}
\hline \multirow[t]{2}{*}{ Metatarsals } & \multicolumn{2}{|c|}{ Rater 1} & \multirow{2}{*}{$\begin{array}{l}\text { Rater } 2 \\
\text { ICC }\end{array}$} & \multicolumn{3}{|c|}{ Rater 3} \\
\hline & $\overline{\mathrm{ICC}}$ & $\mathrm{LCL}$ & & $\overline{\mathrm{LCL}}$ & ICC & $\mathrm{LCL}$ \\
\hline $\mathrm{M1}$ & 0.993 & 0.982 & 0.973 & 0.939 & 0.969 & 0.929 \\
\hline M2 & 0.994 & 0.998 & 0.978 & 0.949 & 0.992 & 0.980 \\
\hline M3 & 0.996 & 0.990 & 0.985 & 0.949 & 0.988 & 0.973 \\
\hline M4 & 0.992 & 0.982 & 0.934 & 0.854 & 0.923 & 0.832 \\
\hline M5 & 0.993 & 0.984 & 0.987 & 0.969 & 0.960 & 0.909 \\
\hline
\end{tabular}

Two-way mixed effects model used where people effects are random and measures effects are fixed. Intra-rater ICC obtained on three repeats of measurements by each rater with $N=15$ 
Table 7 Intraclass correlation coefficients and 95\% lower confidence limit within rater measurements for Barroco's measurement technique

\begin{tabular}{|c|c|c|c|c|c|c|}
\hline \multirow[t]{2}{*}{ Metatarsals } & \multicolumn{2}{|c|}{ Rater 1} & \multicolumn{2}{|c|}{ Rater 2} & \multicolumn{2}{|c|}{ Rater 3} \\
\hline & ICC & $\mathrm{LCL}$ & ICC & $\mathrm{LCL}$ & $\mathrm{ICC}$ & $\mathrm{LCL}$ \\
\hline M1 & 0.987 & 0.969 & 0.966 & 0.923 & 0.986 & 0.968 \\
\hline M2 & 0.997 & 0.993 & 0.985 & 0.965 & 0.988 & 0.971 \\
\hline M3 & 0.992 & 0.982 & 0.969 & 0.930 & 0.983 & 0.960 \\
\hline M4 & 0.993 & 0.983 & 0.937 & 0.861 & 0.974 & 0.940 \\
\hline M5 & 0.987 & 0.969 & 0.883 & 0.752 & 0.953 & 0.895 \\
\hline
\end{tabular}

Two-way mixed effects model used where people effects are random and measures effects are fixed. Intra-rater ICC obtained on three repeats of measurements by each rater with $N=15$

to provide length measurements in their study [32]. In contrast, when testing for inter-rater and intra-rater variability using the $95 \%$ limits of agreement, Chauhan et al. found "high variability" between and within raters using the Maestro technique [36]. This may be due to the time-gap between measurements; while their study collected measurements three months apart, we conducted ours weekly. A comparison of relative metatarsal length in normal feet between our study and Maestro's study is given in Table 8 below. The comparability of metatarsal lengths between the two studies further validates maestro's measurement technique.

Barroco's method of measurement showed inter-rater LCL values between $0.865-0.998$ across all five metatarsals. The intra-rater LCL values were found to be between 0.752-0.993 across all five metatarsals. As we are the first study to investigate the reliability of this measurement technique, there is no relevant literature to support or refute our reliability findings. However the absolute metatarsal lengths in normal feet were comparable between our study and the original Barroco study (Table 9). In both studies index minus foot type was most prevalent with metatarsal formula $1<2>3>4>5$. The observed metatarsal length variability between the two studies could relate to differences in sample size and gender disparity in the study population. Where Barroco et al. studied metatarsal length in 83 male and 83 female normal feet $(n=332 \mathrm{ft})$, our study examined metatarsal length on a total of 15 normal feet from a pooled sample of male and female radiographs. It is well established

Table 8 Comparison of mean relative metatarsal length \pm SEM (in $\mathrm{mm}$ ) in normal feet between Maestro's study and our study

\begin{tabular}{lllll}
\hline & \multicolumn{4}{l}{ Mean \pm SEM (in mm) } \\
\cline { 2 - 5 } & M2-M1 & M2-M3 & M3-M4 & M4-M5 \\
\hline Maestro et al. [43] & $3.3 \pm 0.9$ & $3.3 \pm 0.9$ & $6.5 \pm 1.0$ & $12 \pm 1.9$ \\
$N=40$ & $3.1 \pm 0.3$ & $4.3 \pm 0.4$ & $8.5 \pm 0.4$ & $13.9 \pm 0.4$ \\
Our study & & & & \\
$N=15$ & &
\end{tabular}

that on average male foot is inherently longer than that of a female $[40,41]$.

One limitation of our study was that we couldn't control for any variability stemming from imaging protocol. During the initial investigation of both techniques, we noticed that the angulation of the proximal reference line seemed to depend on the rear-foot positioning (Fig. 2 ) as also mentioned by Deleu et al. [32]. For example, a significantly pronated versus supinated foot may have influenced the angulation of the proximal reference line [32]. Future studies can standardise the rear-foot positioning by taking the weight-bearing DP radiographs in neutral calcaneal stance position (NCSP). Furthermore prospective studies could consider standardising $\mathrm{x}$-ray imaging conditions (e.g. X-ray source inclination of $15^{\circ}$ with beam centred between the navicular bones, distance from the foot to the $X$ ray source $=1 \mathrm{~m}$ ) as also suggested by previous studies to minimise sources of variability [2, 35].

Though we excluded any forefoot pathology in our study sample, presence of forefoot deformity such as hallux valgus is likely to change the SM4 reference line by changing the fibular sesamoid position in Maestro's technique. But because the measurement is the measurement of relative lengths or distances, this doesn't change the reliability of the measurement technique. In fact Maestro has reported excellent intra-observer and inter-observer reproducibility in metatarsal length measurement in feet with hallux valgus and rigidus [35].

The practicality of both methods should not be overlooked. The Barroco technique requires only one line to be drawn between easily recognisable points before making metatarsal length measurements. It is simple, easy to use on any foot morphotypes, to little variation and does not require complex instruments. The Maestro technique requires several steps, each dependent on the other. This may be more time consuming and requires proper training to conduct measurements.

We believe that the use of both Maestro and Barroco methods may help clinicians in the peri-operate planning relating to forefoot procedures. The subsequent biomechanical implications following shortening osteotomies and general forefoot procedures are not well understood at this stage $[24,25,42]$. The use of objective metatarsal length measurements peri-operatively using the Maestro and/or Barroco techniques can lead to better understanding in this field.

\section{Conclusion}

This study shows that both the Maestro and Barroco metatarsal length measurement techniques produce high to very high repeatability and reproducibility 
Table 9 Comparison of mean relative metatarsal length and standard deviation (SD) in millimetres in normal feet between Barroco and our study

\begin{tabular}{|c|c|c|c|c|c|c|c|c|c|c|}
\hline & \multicolumn{10}{|c|}{ Mean (SD) (in mm) } \\
\hline & \multicolumn{2}{|l|}{ M1 } & \multicolumn{2}{|l|}{$\mathrm{M} 2$} & \multicolumn{2}{|l|}{ M3 } & \multicolumn{2}{|l|}{ M4 } & \multicolumn{2}{|l|}{ M5 } \\
\hline & Male & $\overline{\text { Female }}$ & Male & $\overline{\text { Female }}$ & Male & $\overline{\text { Female }}$ & Male & $\overline{\text { Female }}$ & Male & Female \\
\hline Barroco et al. [2] & 125.4 & 115.1 & 127.8 & 117.3 & 123.4 & 113.5 & 114.2 & 105.3 & 99.5 & 91.7 \\
\hline \multicolumn{11}{|l|}{$N=83$ male } \\
\hline$N=83$ female & $(8.2)$ & (7.4) & $(8.2)$ & $(7.3)$ & $(8.0)$ & $(7.2)$ & $(7.7)$ & $(7.2)$ & (7.9) & $(7.4)$ \\
\hline $\begin{array}{l}\text { Our study } \\
{ }^{*} N=15\end{array}$ & \multicolumn{2}{|c|}{$122.8(10)$} & \multicolumn{2}{|c|}{$124.2(11)$} & \multicolumn{2}{|c|}{$119.0(11)$} & \multicolumn{2}{|c|}{$109.0(10)$} & \multicolumn{2}{|c|}{$94.6(9)$} \\
\hline
\end{tabular}

${ }^{*} N=15$ includes male and female subjects

across all five metatarsals. We deem both methods reliable for the purpose of forefoot procedures peri-operative planning and research investigating metatarsal length and forefoot pathology. We found both methods very practical to conduct. The novel Barroco method was more simplistic. Our study supports the use of this method for future use.

\section{Abbreviations}

DICOM: Digital imaging and communications in medicine; DP: Dorsoplantar; ICC: Intraclass correlation coefficient; LCL: Lower-confidence limits; M1-M5: Metatarsal one to metatarsal five

\section{Acknowledgements}

The authors would like to thank the two independent raters Amanda Cordeiro and Muhammad Rais for their contributions. We also like to acknowledge and thank Dr. Sue Miller for assisting with the statistical analysis and Professor Barry lacopetta for his support throughout.

\section{Funding}

The authors received no financial funding for this research.

\section{Availability of data and materials}

The datasets used and/or analysed during the current study are available from the corresponding authors on reasonable request.

\section{Authors' contributions}

RN contributed to the conception and design of the study. ZA and HK collected and randomised the data allocation. NW with two other independent raters performed radiological measurements. ZA conducted the statistical analysis, wrote the results, the references edited and finalised the manuscript. HK and NW wrote the introduction and discussion and contributed in manuscript editing. All authors read and approved the final manuscript.

\section{Ethics approval and consent to participate}

The University of Western Australia's human ethics board approved this study (no. RA/4/1/8153). All participants had signed an informed consent form allowing their podiatric radiographs to be used for future research by the University of Western Australia (UWA) podiatry clinic.

\section{Consent for publication}

Not applicable.

\section{Competing interests}

The authors declare that they have no competing interests.

\section{Publisher's Note}

Springer Nature remains neutral with regard to jurisdictional claims in published maps and institutional affiliations.
Received: 5 May 2018 Accepted: 31 July 2018

Published online: 16 August 2018

\section{References}

1. Young CC, Niedfeldt MW, Morris GA, Eerkes KJ. Clinical examination of the foot and ankle. Primary care. 2005;32(1):105-32.

2. Barroco R, Nery C, Favero G, Mombach R, Nascimento O, Jorge S, et al. Evaluation of Metatarsal Relationships in the Biomechanics of 332 Normal Feet Using the Method of Measuring Relative Lengths. Rev Bras Ortop. 2011;46(4):431-8.

3. Dominguez-Maldonado G, Munuera-Martinez PV, Castillo-Lopez JM, RamosOrtega J, Albornoz-Cabello M. Normal values of metatarsal parabola arch in male and female feet. ScientificWorldJournal. 2014;2014:505736.

4. Morton MJ. Structural factors in static disorders of the foot. Am J Surg. 1930;9(2):315-28.

5. Morton MJ. The Human Foot. Its Evolution, Physiology and Functional Disorders. Postgrade Med J. 1940;16(177):270.

6. Nilsonne H. Hallux Rigidus and Its Treatment. Acta Orthopaedica Scandinavica. 1930;1-4(1):295-303.

7. Viladot A. Metatarsalgia due to biomechanical alterations of the forefoot. Orthop Clin North Am. 1973;4(1):165-78.

8. Glasoe WM, Coughlin MJ. A critical analysis of Dudley Morton's concept of disordered foot function. J Foot Ankle Surg. 2006;45(3):147-55.

9. Maceira $\mathrm{E}$, Monteagudo M. Transfer metatarsalgia post hallux valgus surgery. Foot Ankle Clin. 2014;19(2):285-307.

10. Hardy RH, Clapham JC. Observations on hallux valgus; based on a controlled series. J Bone Joint Surg Br. 1951:33-B(3):376-91.

11. Lundberg BJ, Sulja T. Skeletal parameters in the hallux valgus foot. Acta Orthop Scand. 1972;43(6):576-82.

12. Mancuso JE, Abramow SP, Landsman MJ, Waldman M, Carioscia M. The zero-plus first metatarsal and its relationship to bunion deformity. J Foot Ankle Surg. 2003;42(6):319-26.

13. Munuera PV, Polo J, Rebollo J. Length of the first metatarsal and hallux in hallux valgus in the initial stage. Int Orthop. 2008;32(4):489-95.

14. Saragas NP, Becker PJ. Comparative radiographic analysis of parameters in feet with and without hallux valgus. Foot Ankle Int. 1995;16(3):139-43.

15. Bryant A, Tinley $P$, Singer K. A comparison of radiographic measurements in normal, hallux valgus, and hallux limitus feet. J Foot Ankle Surg. 2000;39(1):39-43.

16. Naraghi R, Bremner A, Slack-Smith L, Bryant A. Radiographic Analysis of Feet With and Without Morton's Neuroma. Foot Ankle Int. 2017;38(3):310-7.

17. Kaipel M, Krapf D, Wyss C. Metatarsal length does not correlate with maximal peak pressure and maximal force. Clin Orthop Relat Res. 2011:469(4):1161-6.

18. Menz HB, Fotoohabadi MR, Munteanu SE, Zammit GV, Gilheany MF. Plantar pressures and relative lesser metatarsal lengths in older people with and without forefoot pain. J Orthop Res. 2013;31(3):427-33.

19. Naraghi R, Slack-Smith L, Bryant A. Plantar Pressure Measurements and Geometric Analysis of Patients With and Without Morton's Neuroma. Foot Ankle Int. 2018; https://doi.org/10.1177/1071100718766553.

20. Rodgers MM, Cavanagh PR. Pressure distribution in Morton's foot structure. Med Science Sports Exer. 1989;21(1):23-8.

21. Weber JR, Aubin PM, Ledoux WR, Sangeorzan BJ. Second metatarsal length is positively correlated with increased pressure and medial deviation of the 
second toe in a robotic cadaveric simulation of gait. Foot Ankle Int. 2012;33(4):312-9.

22. Bhutta MA, Chauhan D, Zubairy Al, Barrie J. Second metatarsophalangeal joint instability and second metatarsal length association depends on the method of measurement. Foot Ankle Int. 2010;31 (6):486-91.

23. Arie EK, Moreira NS, Freire GS, Dos Santos BS, Yi LC. Study of the metatarsal formula in patient with primary metatarsalgia. Rev Bras Ortop. 2015;50(4):438-44.

24. Barouk LS. Weil's metatarsal osteotomy in the treatment of metatarsalgia. Orthopade. 1996;25(4):338-44.

25. Vandeputte G, Dereymaeker G, Steenwerckx A, Peeraer L. The Weil osteotomy of the lesser metatarsals: a clinical and pedobarographic follow-up study. Foot Ankle Int. 2000;21(5):370-4.

26. Perez-Munoz I, Escobar-Anton D, Sanz-Gomez TA. The role of Weil and triple Weil osteotomies in the treatment of propulsive metatarsalgia. Foot Ankle Int. 2012;33(6):501-6.

27. Park EH, Kim YS, Lee HJ, Koh YG. Metatarsal shortening osteotomy for decompression of Morton's neuroma. Foot Ankle Int. 2013;34(12):1654-60.

28. Devos Bevernage B, Leemrijse T. Predictive value of radiographic measurements compared to clinical examination. Foot Ankle Int. 2008;29(2):142-9.

29. Fowler A. A method of forefoot reconstruction. J Bone Joint Surg. 1959: 41B(3):507-13.

30. Breusch SJ, Sharp RJ, Wenz W, Taylor L. Morton's neuroma following first metatarsal osteotomy. Orthopedics. 1998;21 (12):1287-8.

31. Kuo CH, Huang PJ, Cheng YM, Huang KY, Chen TB, Chen YW, et al. Modified Mitchell osteotomy for hallux valgus. Foot Ankle Int. 1998;19(9):585-9.

32. Deleu PA, Pod H, Leemrijse T, Birch I, Vande Berg B, Bevernage BD. Reliability of the Maestro radiographic measuring tool. Foot Ankle Int. 2010;31(10):884-91.

33. Coughlin MJ. Second metatarsophalangeal joint instability in the athlete. Foot Ankle. 1993;14(6):309-19.

34. Davies MS, Saxby TS. Metatarsal neck osteotomy with rigid internal fixation for the treatment of lesser toe metatarsophalangeal joint pathology. Foot Ankle Int. 1999;20(10):630-5.

35. Maestro M, Besse JL, Ragusa M, Berthonnaud E. Forefoot morphotype study and planning method for forefoot osteotomy. Foot Ankle Clin. 2003;8(4):695-710.

36. Chauhan DBM, Barrie JL. Does it matter how we measure metatarsal length? Foot Ankle Surg. 2011;17(3):124-7.

37. Shima H, Okuda R, Yasuda T, Jotoku T, Kitano N, Kinoshita M. Radiographic measurements in patients with hallux valgus before and after proximal crescentic osteotomy. J Bone Joint Surg Am. 2009;91(6):1369-76.

38. Bujanga MA, Baharum N. A simplified guide to determination of sample size requirements for estimating the value of intraclass correlation coefficient: a review. Arch Orof Sci. 2017;12(1):1-11.

39. Viera AJ, Garrett JM. Understanding interobserver agreement: the kappa statistic. Fam Med. 2005;37(5):360-3.

40. Manna I, Pradhan D, Ghosh S, Kar SK, Dhara P. A comparative study of foot dimension between adult male and female and evaluation of foot hazards due to using of footwear. J Physiol Anthropol Appl Human Sci. 2001;20(4):241-6.

41. Luo G, Houston VL, Mussman M, Garbarini M, Beattie AC, Thongpop C Comparison of male and female foot shape. J Am Podiatr Med Assoc. 2009;99(5):383-90.

42. Sharma DK, Roy N, Shenolikar A. Weil Osteotomy of lesser metatarsals for metatarsalgia: A clinical and radiological follow-up. Foot. 2005;15(4):202-5.

43. Maestro M, Augoyard M, Barouk L, Benichou M, Peyror J, Ragusa Mea. Biomechnics and radiological markers of the lateral sesamoid of th ehallux in relation to the lesser metatrsal blade. Med et chir du pied. 1995;3:145-54.

Ready to submit your research? Choose BMC and benefit from:

- fast, convenient online submission

- thorough peer review by experienced researchers in your field

- rapid publication on acceptance

- support for research data, including large and complex data types

- gold Open Access which fosters wider collaboration and increased citations

- maximum visibility for your research: over $100 \mathrm{M}$ website views per year

At BMC, research is always in progress.

Learn more biomedcentral.com/submissions 